\title{
Clinical update on hypomethylating agents
}

\author{
Matthieu Duchmann ${ }^{1,2} \cdot$ Raphael Itzykson ${ }^{1,3}$
}

Received: 1 April 2019 / Revised: 11 April 2019 / Accepted: 15 April 2019 / Published online: 24 April 2019

(C) Japanese Society of Hematology 2019

\begin{abstract}
Hypomethylating agents (HMAs), azacitidine and decitabine, are standards of care in higher-risk myelodysplastic syndromes and in acute myeloid leukemia patients ineligible for intensive therapy. Over the last 10 years, research efforts have sought to better understand their mechanism of action, both at the molecular and cellular level. These efforts have yet to robustly identify biomarkers for these agents. The clinical activity of HMAs in myeloid neoplasms has been firmly established now but still remains of limited magnitude. Besides optimized use at different stages of the disease, most of the expected clinical progress with HMAs will come from the development of second-generation compounds orally available and/or with improved pharmacokinetics, and from the search, so far mostly empirical, of HMA-based synergistic drug combinations.
\end{abstract}

Keywords Hypomethylating agents · Myeloid malignancies $\cdot$ Myelodysplastic syndromes $\cdot$ Acute myeloid leukemia . Chronic myelomonocytic leukemia

\section{Introduction}

Azacitidine (5-azacitidine, AZA) and decitabine (5-aza-2'deocytidicine, DAC) are two analogues of cytidine able, at low but clinically relevant concentrations, to inhibit DNA methyltransferases (DNMTs), resulting in transient and variable DNA hypomethylation. These so-called 'hypomethylating agents' (HMAs) are active in myeloid malignancies, including myelodysplastic syndromes (MDS), chronic myelomonocytic leukemia (CMML) and acute myeloid leukemia (AML). However, responses are heterogenous and rarely sustained. This review provides an update on the use of HMAs in myeloid malignancies. We will also provide an overview of the developing applications of HMAs, the efficacy of new HMAs currently in development and the utility of HMA-based combinations.

Raphael Itzykson

raphael.itzykson@aphp.fr

1 INSERM/CNRS UMR 944/7212, Saint-Louis Research Institute, Paris Diderot University, Paris, France

2 Hematology Laboratory, Hôpital Saint-Louis, Assistance Publique Hôpitaux de Paris, Paris, France

3 Clinical Hematology Department, Hôpital Saint-Louis, Assistance Publique Hôpitaux de Paris, Avenue Claude Vellefaux, 75010 Paris, France

\section{Mechanism of action of HMA}

The metabolism of HMAs has recently been reviewed in detail [1], and is summarized in Fig. 1. After absorption, HMAs are instable in plasma owing to spontaneous hydrolysis and deamination by cytidine deaminase (CDA), explaining their relative short plasma half-life [2]. Following their cellular uptake, which is dependent on nucleoside transporters, they are successively phosphorylated by intracellular kinases. The active tri-phosphorylated metabolite of DAC (5-aza-dCTP) is directly incorporated into DNA during cell cycle. Regarding AZA, the majority of 5-aza-CTP is incorporated in RNA, whereas a minority is converted in 5-azadCTP by the ribonucleotide reductase and is incorporated in DNA during replication.

5-aza-dCTP incorporated into DNA binds DNMT1 and leads to its degradation, promoting a progressive DNA hypomethylation after several rounds of replication. This has been postulated to lead to an activation of repressed tumor suppressor genes [3], inducing senescence and apoptosis. HMAs can also allow expression of tumor-associated antigens [4] that can trigger anti-tumoral immune response [5]. In solid tumors, HMAs promote the expression of endogenous retroviral elements leading to an interferon-dependent cell killing $[6,7]$. Whether a similar phenomenon occurs in myeloid malignancies remains to be investigated. Finally, 
Fig. 1 Molecular and cellular mechanisms of action of hypomethylating agents

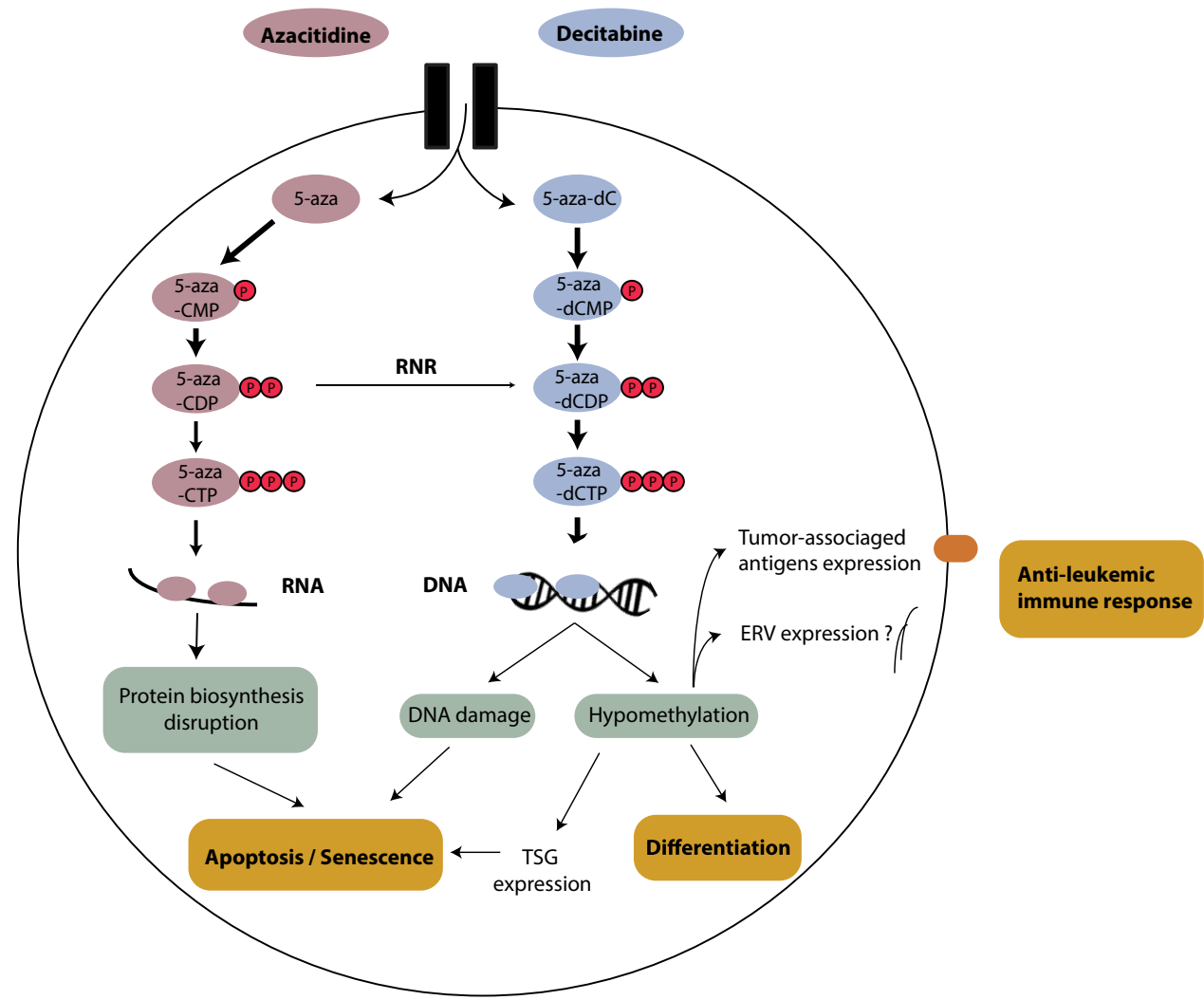

AZA have been shown to promote differentiation of leukemic cells in vivo in a tet2-mutated AML mouse model [8]. Besides these demethylating effects, DNA-incorporated 5-aza-dCTP can also induce DNA damage [9], although this effect is likely limited with current administration schemes of AZA and DAC, aiming at hypomethylation rather than cytotoxicity. Finally, incorporation of 5-aza-CTP in RNA may disrupt protein synthesis [10], a phenomenon that may also promote apoptosis. A novel mass spectrometry method has been developed to quantify the abundance of AZA incorporated in RNA, DNA and cytoplasm. This method showed that incorporation in DNA but not RNA seems to be the rate limiting step for response [11].

\section{Approved use of HMA in hematological malignancies}

\section{In myelodysplastic syndromes}

Since the AZA-001 study, AZA is the standard of care in higher-risk MDS not eligible for allogeneic stem cell transplant (ASCT). This randomized phase III trial showed that AZA was superior to best supportive care, low-dose aracytine or intensive chemotherapy, as it improved overall survival and delayed AML transformation in higher-risk MDS and low-blast count AML elderly patients [12]. Decitabine is also active in higher-risk MDS, but clinical trials failed to show an improvement in overall survival, possibly owing to trial design [13]. HMAs have been used as first-line therapy in lower-risk MDS [14, 15]. However, addition of AZA in patients who fail to respond to erythropoiesis-stimulating agents (ESA) has shown limited efficacy [16]. AZA and DAC are both licensed for MDS in the US, whereas only AZA is approved in int2/high-risk MDS in Europe.

\section{In chronic myelomonocytic leukemia}

Small non-randomized prospective trials have reported activity of AZA [17] and DAC [18] in CMML. Because of the limited efficacy of conventional chemotherapy in CMML-2 and because the AZA-001 trial included some CMML-2 patients, AZA but not DAC was approved in Europe for CMML-2. Again, both drugs are approved in CMML by FDA. A prospective randomized phase III clinical trial comparing DAC (with or without hydroxyurea) versus hydroxyurea alone is currently ongoing to evaluate the efficacy of DAC in proliferative CMML (NCT02214407).

\section{In acute myeloid leukemia}

A subgroup analysis of the AZA-001 trial focusing on low-blast count AML [19], and a large randomized phase III trial in elderly AML patients with bone marrow blast 
counts $>30 \%$ showed that AZA improved survival compared to conventional care in older AML patients deemed ineligible for intensive chemotherapy [20]. The survival benefit was particularly apparent in high-risk subgroups with adverse cytogenetics or myelodysplasia-related changes [21]. DAC showed activity in older patients with poor/intermediate risk, but failed to improve survival when compared to best supportive care or low-dose AraC [22]. AZA and DAC are licensed for the treatment of low-blast count AML in US, whereas both are licensed in Europe for AML unfit for ASCT regardless of the blast count.

\section{Biomarkers of response to HMAs}

Only a subset of patients achieve response with HMAs alone. Moreover, responses are rarely sustained and are loosely correlated with prolonged survival $[12,18,20]$. Accumulative evidence suggests that HMAs mostly target secondary clones [23-25], whereas founder clones are spared and can acquire additional mutations, eventually leading to relapse [23-27]. Identification of robust biomarkers of response and survival with HMAs is thus warranted.

As gene mutations implicated in methylation are frequently mutated in myeloid malignancies, their impact on response to HMAs has been extensively investigated. Indeed, the presence of TET2 mutations has been associated with a higher likelihood of response in MDS [28-31] and CMML [32], especially in the absence of ASXL1 mutations. Mutations in other methylation regulators DNMT3A [30, 31, $33]$ and $I D H 1 / 2[31,34]$ may also predict response in AML and MDS. Whether TP53 mutations, which are classically associated with a poor prognosis, can be cleared by intensive DAC regimens remains controversial [18, 35-38]. This lack of robust association between mutational status and HMA benefit may be explained by the interaction between mutations, and by intra-tumoral heterogeneity. Indeed, in MDS and AML treated with AZA, lower clonal burden of secondary mutations in leukemic progenitors is associated with a higher response rate [23].

There is no correlation between baseline promoter methylation and response [39, 40], perhaps owing to intratumoral epigenetic heterogeneity [41]. However, an epigenetic classifier including analysis of distal enhancers has been developed in CMML, where it has been shown to predict response to DAC $[42,43]$. Future studies will be required to determine the robust enhancer signatures predicting HMA activity. These will be facilitated by continuous technological progresses in assessing the methylome [44].

Chromatin organization may also influence HMA response [45]. Indeed, the RNA: ${ }^{5} \mathrm{C}$ methyltransferase NSUN1 binds BRD4 and RNA-polymerase-II to form active chromatin structures that are insensitive to AZA. In samples from AZA-resistant MDS and AML, there is a significant increase in NSUN1/BRD4 recruitment to active chromatin that may be responsible for the AZA resistance. 5-Aza-dCTP is incorporated into DNA during the cell cycle. Recent data suggest patients resistant to AZA have more quiescent leukemic progenitors at treatment onset than responders [23, 25].

Finally, pharmacogenomics may explain in part the response heterogeneity. Indeed, somatic mutations and/or aberrant expression of genes encoding proteins implicated in HMAs uptake like hENT1 [46, 47], or in HMA metabolism like UCK and DCK kinases [47-49] have been reported in resistant MDS and AML. Increased activity of CDA, implicated in HMA degradation, is also associated with resistance to HMA [48]. Polymorphisms affecting CDA activity can predict response to other cytosin analogues [50,51].

\section{New regimen for HMAs}

\section{Intensive therapy}

Intensified schedules of HMAs have shown promising results in AML and MDS. A 10-day regimen of DAC in MDS and AML leads to high response rates in high-risk cytogenetic and TP53-mutated patients [35]. A recent study reported that an intensified schedule of AZA $\left(75 \mathrm{mg} / \mathrm{m}^{2}\right.$, d1-5 every 14 days) in high-risk MDS can also lead to high response rates [52]. Thus, intensified regimens could increase the efficacy of HMAs, probably at the expense of increased toxicity, prompting their randomized comparison with standard regimens.

\section{Maintenance therapy}

HMAs are active in relapsed or refractory myeloid malignancies, including after intensive treatment or ASCT [53]. Because of their ability to promote anti-tumor immune response, maintenance treatment with HMAs has been proposed to prevent relapse in patients who achieved CR. Pilot studies have shown the feasibility of the post-transplant maintenance with HMAs, despite significant toxicity leading to decreased dose of HMAs [53]. This led to the ongoing phase III randomized trial VZ-AML-PI-0129 that evaluates the efficacy of azacitidine maintenance $(32 \mathrm{mg} /$ $\mathrm{m}^{2}$, day 1-5) versus placebo after ASCT in AML and MDS (NCT00887068). The oral formulation of AZA, CC-486, has a good tolerance profile in post-transplant maintenance in AML and MDS [54] and may facilitate dose adaptation and adherence to treatment. CC-486 is currently evaluated as a maintenance therapy after intensive chemotherapy in previously untreated AML (QUAZAR AML-001, NCT01757535) and as a maintenance therapy after ASCT in AML and MDS patients (NCT01835587). 
Following several negative or underpowered trials [55-57], the HOVON conducted a trial where high-risk MDS or AML patients older than 60 years, in CR/CRi after 2 courses of intensive chemotherapy were randomized to 12 cycles of attenuated dose AZA (50 mg/m², day 1-5) or observation. This trial was the first to show a prolonged disease-free survival (DFS) with AZA. Although this did not translate in a meaningful OS benefit, probably owing to the limited number of patients accrued $(n=116)$, this study provides proof of concept for epigenetic therapy as a maintenance therapy in older AML [58].

\section{Preemptive treatment}

Another strategy to prevent relapse is to initiate a treatment as soon as there is evidence of incipient relapse, such as an increase in minimal residual disease (MRD). In the RELAZA-2 phase II trial, authors monitored AML and MDS patients achieving CR after intensive chemotherapy or ASCT and began AZA in MRD+ patients [59]. Despite the lack of a randomized control group, preemptive treatment with AZA might delay relapse in MRD+ patients compared to historical data, especially in patients with lower levels of MRD. These results should however be confirmed in a randomized trial.

\section{Treatment of inflammatory manifestations associated to myeloid malignancies}

Systemic autoimmune and inflammatory disorders (SAID) are present in up to $30 \%$ of MDS/CMML patients. HMA can control these manifestations, including in steroid-dependent or -resistant SAID. HMA activity on myeloid neoplasm and SAID was concordant in most cases [60], suggesting that this activity is caused by reversal of paracrine influence of leukemic cells on the immune system, rather than a direct action on the immune system. A phase II study is currently ongoing to evaluate the efficacy of AZA on steroid-dependent/resistant SAID in MDS and CMML patients (NCT02985190).

\section{New hypomethylating agents}

\section{Oral azacitidine (CC-486)}

CC-486 is an oral formulation of 5-azacitidine which has been developed to simplify AZA administration and dose adaptation, and eventually increase leukemic cells exposition to AZA [61]. CC-486 is active in AML, CMML and MDS [62], including low-risk MDS [63], with an acceptable safety profile. The phase III QUAZAR trial (NCT01566695) is currently comparing CC-486 to placebo in low-risk MDS patients with anemia or thrombocytopenia. Activity of
CC-486 is also investigated as a maintenance therapy after intensive chemotherapy (NCT01757535) and after ASCT (NCT01835587) in AML and MDS patients.

\section{Guadecitabine}

Guadecitabine is a dinucleotide of DAC and deoxyguanosine. It was developed to be resistant to CDA, leading to a longer exposure of leukemic cells to the active metabolite of DAC [64]. It is administered sub-cutaneously. Guadecitabine is well tolerated and active in untreated [65] and relapsed/ refractory [66] MDS and AML, and the schedule of 5 days at $60 \mathrm{mg} / \mathrm{m}^{2}$ has the best safety profile. Two phase III trials have evaluated guadecitabine versus treatment of choice in untreated AML patients unfit for intensive chemotherapy (ASTRAL-1 trial, NCT02348489), and in relapsed/refractory AML (ASTRAL-2, NCT02920008). The sponsors of ASTRAL-1 have announced that the trial had failed to meet its co-primary endpoints of superior CR rate and prolonged overall survival, but the detailed scientific report of this trial has not been made available yet (https://www.otsuka.co.jp/ en/company/newsreleases/2018/20180731_1.html). Guadecitabine is also compared to conventional care in MDS and CMML previously treated with HMA in a phase III study (NCT02907359).

\section{Astx727}

An oral formulation of DAC is currently in development. ASTX727 is an association of DAC with the CDA inhibitor cedazuridine (E7727). Pharmacokinetic analysis in MDS and CMML revealed similar DAC exposition between a standard 5-day IV DAC course and 5 days of oral ASTX727 [67]. The treatment was well tolerated, and response rate was $61 \%$.

\section{Combinations based on HMAs}

\section{Combination with histone deacetylase (HDAC) inhibitors}

In myeloid malignancies, deacetylation of histone tails can participate in silencing tumor suppressor genes. HDAC inhibitors (HDACi) in monotherapy are modestly active in high-risk MDS and AML, and in vitro evidence supported the synergy between HMAs and HDACi [68]. However, randomized trials have repeatedly failed to demonstrate a benefit for the combination of HMA with HDACi including entinostat [69], valproic acid [70, 71], vorinostat [72, 73] or pracinostat [74]. The combinations were potentially hampered by increased toxicity, and one study even suggested 
an antagonism between AZA and entinostat, perhaps owing to the reduction of proliferation by HDACi [75].

\section{Combination with lenalidomide}

Lenalidomide is active in del(5q) MDS, where it induces synthetic lethality by promoting degradation of $\mathrm{CK} 1 \alpha$, which is encoded by a gene located in the deleted regions of these diseases [76]. Lenalidomide also promotes erythropoiesis in non-del(5q) MDS [77]. The rationale of its association with azacitidine in multiple trials with various regimens was largely empirical, and multiple randomized studies in non-del $(5 q)$ higher-risk MDS, CMML and AML failed to demonstrate a benefit for the combination [71,73].

\section{Combination with sapacitabine}

Sapacitabine, an oral cytarabine analogue, is active in monotherapy in AML [78]. However, the large randomized phase III trial SEAMLESS comparing DAC to alternating cycles of DAC and sapacitabine in older untreated AML failed to demonstrate a survival advantage in the experimental group [79].

\section{Combination with checkpoint inhibitors}

Gene mutations and epigenetic abnormalities give rise to expression of tumor-associated antigens that can be recognized by the immune system. However, checkpoint proteins overexpressed by tumor and T cells from AML [80] and MDS [81] cells can lead to exhaustion of immune cells and thus evasion from anti-leukemia immunity. Inhibitors of the CLTA-4 and PD-1 checkpoints are efficient in solid tumors. Studies so far reported modest activity in myeloid malignancies [82]. Their combination with HMAs in these diseases is attractive as HMAs can enhance anti-tumor immune response by inducing expression of endogenous retroviral elements [6,7] and tumor-associated antigens [4], as well as induce overexpression of checkpoint molecules by $\mathrm{T}$ cells at the same time [81]. Several clinical trials evaluating azacitidine with anti-PD1 nivolumab (NCT02397720, NCT02397720), anti-PDL1 durvalumab (NCT02775903), anti-PDL1 atezolizumab (NCT02508870) and the combination nivolumab + anti-CTLA-4 ipilimumab (NCT02397720) in myeloid malignancies are currently ongoing. The nonrandomized phase II trial evaluating AZA+ nivolumab in relapsed/refractory AML reported moderate response rates, and manageable immune-related adverse events [83]. Nonresponders were shown to express higher rates of CTLA-4 on T cells. Anti-CTLA-4 ipilimumab is active in association to AZA in AML [84] and a phase II trial is currently evaluating the combination AZA+ nivolumab with or without ipilimumab in those diseases (NCT02397720).

\section{Combination with venetoclax}

BCL-2 is an anti-apoptotic protein frequently overexpressed in myeloid malignancies, and is a potential vulnerability of leukemic stem cells (LSCs) $[85,86]$. Venetoclax is a specific inhibitor of BCL-2 which is active in AML, with modest single-agent activity in relapsed AML [87]. Ex vivo studies have highlighted a synergy between venetoclax and HMA [88], justifying the evaluation of the combination. The phase Ib trial evaluating the combination VEN + HMA in untreated AML of the elderly reported an acceptable tolerance with probably more myelosuppression than with HMAs alone, but high response rates (composite CR rate 73\%) [89]. In this study, $400 \mathrm{mg}$ of venetoclax seemed to have the best safety profile while providing deep and durable responses in this poor-risk population, although the follow-up duration of this cohort is still limited. HMAs + VEN combination has also been reported to provide a response when used as a salvage therapy in relapsed/refractory AML and MDS patients [90]. Detailed biological studies have shown that the combination of HMAs with VEN uniquely altered the metabolic activity of LSCs, possibly explaining the high rate of flow cytometry-based MRD negativity in AML patients treated upfront with the combination [86]. Thus, the combination of HMAs and VEN has the potential to challenge single-agent HMA therapy in the near future, although this will require additional studies and prolonged follow up.

\section{Combination with IDH inhibitors}

$I D H 1$ and $I D H 2$ mutations are frequent in myeloid malignancies, and lead to a gain of function with production of the oncometabolite 2-hydroxyglutarate (2-HG). 2-HG inhibits $\alpha$-ketoglutarate-dependent enzymes such as TET2, leading to a dysregulation of methylation. Selective inhibitors of IDH2 mutations enasidenib (AG-221 [91]) and of IDH1 mutations ivosidenib (AG-120 [92]) have shown efficacy in monotherapy in relapsed/refractory AML. Preliminary results from a phase $1 \mathrm{~b} / 2$ trial (NCT02677922) in untreated AML report efficiency of the association in older patients with newly diagnosed AML [93]. Evaluation of the ivosidenib + AZA combination is ongoing in the randomized phase 3 AGILE trial (NCT03173248).

\section{Combination with pevonidestat}

Pevonedistat (PEV) is an inhibitor of NEDD8-activating enzyme modestly active as a single agent in relapsed or refractory MDS and AML [94]. A high-throughput ex vivo screen in AML cells showed a synergy between PEV and HMAs [95]. A phase 1b study in untreated elderly AML unfit for intensive chemotherapy that evaluated PEV in association with AZA [96] reported an acceptable safety 
profile with an overall response rate of $50 \%$. The randomized phase 3 clinical trial PANTHER is currently comparing AZA + PEV to AZA alone in untreated MDS, CMML and low-blast count AML (NCT03268954).

\section{Conclusion}

HMAs have been used in myeloid malignancies for more than a decade. Progress in single cell epigenomics should help in improving our understanding of HMAs' mechanisms of action. This will eventually help us to identify robust biomarkers to predict which patients will benefit from the HMA treatment. The spectrum of HMA indications is currently widening, especially as a maintenance or preemptive treatment. Second-generation HMAs are being evaluated in myeloid malignancies. Preliminary results show they may not be superior to AZA or DAC, but oral formulation is at least more convenient and will certainly optimize compliance and dose adaptation. Combinations may finally prove superior to single agents. Whether they should be sought empirically or through a rational pre-clinical screen remains uncertain. Nevertheless, HMAs have the potential to remain an important part of the armamentarium against myeloid neoplasms in the coming decade.

\section{Compliance with ethical standards}

Conflict of interest MD declares no competing financial interests. RI has received research funding from Janssen, Novartis and Oncoethix (now Merck), honoraria from Sanofi, BMS and Celgene and consulting fees from Novartis, Otsuka Pharma, Jazz Pharmaceuticals, Karyopharm, StemLine Therapeutics and Abbvie.

\section{References}

1. Diesch J, Zwick A, Garz A-K, Palau A, Buschbeck M, Götze KS. A clinical-molecular update on azanucleoside-based therapy for the treatment of hematologic cancers. Clin Epigenet. 2016;8:71.

2. Chabner BA, Drake JC, Johns DG. Deamination of 5-azacytidine by a human leukemia cell cytidine deaminase. Biochem Pharmacol. 1973;22:2763.

3. Gonzalez-Zulueta M, Bender CM, Yang AS, Nguyen T, Beart RW, Van Tornout JM, et al. Methylation of the 5' CpG Island of the p16/CDKN2 tumor suppressor gene in normal and transformed human tissues correlates with gene silencing. Cancer Res. 1995;55:4531-5.

4. Goodyear O, Agathanggelou A, Novitzky-Basso I, Siddique S, McSkeane T, Ryan G, et al. Induction of a CD8+ T-cell response to the MAGE cancer testis antigen by combined treatment with azacitidine and sodium valproate in patients with acute myeloid leukemia and myelodysplasia. Blood. 2010;116:1908-18.

5. Li H, Chiappinelli KB, Guzzetta AA, Easwaran H. Immune regulation by low doses of the DNA methyltransferase inhibitor 5 -azacitidine in common human epithelial cancers. Oncotarget. 2014;5:587.
6. Chiappinelli KB, Strissel PL, Desrichard A. Inhibiting DNA methylation causes an interferon response in cancer via dsRNA including endogenous retroviruses. Cell. 2015;162:974.

7. Roulois D, Loo Yau H, Singhania R, Wang Y, Danesh A, Shen $\mathrm{SY}$, et al. DNA-demethylating agents target colorectal cancer cells by inducing viral mimicry by endogenous transcripts. Cell. 2015;162:961-73.

8. Shih AH, Meydan C, Shank K, Garrett-Bakelman FE, Ward PS, Intlekofer AM, et al. Combination targeted therapy to disrupt aberrant oncogenic signaling and reverse epigenetic dysfunction in IDH2- and TET2-mutant acute myeloid leukemia. Cancer Discov. 2017;7:494-505.

9. Palii SS, Emburgh BO, Sankpal UT. DNA methylation inhibitor 5-Aza-2'-deoxycytidine induces reversible genome-wide DNA damage that is distinctly influenced by DNA methyltransferases 1 and 3B. Mol Cell Biol. 2008;28:752.

10. Schaefer M, Hagemann S, Hanna K, Lyko F. Azacytidine inhibits RNA methylation at DNMT2 target sites in human cancer cell lines. Cancer Res. 2009;69:8127.

11. Unnikrishnan A, Vo ANQ, Pickford R, Raftery MJ, Nunez AC, Verma A, et al. AZA-MS: a novel multiparameter mass spectrometry method to determine the intracellular dynamics of azacitidine therapy in vivo. Leukemia. 2017;32:900.

12. Fenaux P, Mufti GJ, Hellstrom-Lindberg E. Efficacy of azacytidine compared with that of conventional care regimens in the treatment of higher-risk myelodysplastic syndromes: a randomised, open-label, phase III study. Lancet Oncol. 2009;10:223.

13. Lübbert M, Suciu S, Baila L, Rüter BH, Platzbecker U, Giagounidis A, et al. Low-dose decitabine versus best supportive care in elderly patients with intermediate- or high-risk myelodysplastic syndrome (MDS) ineligible for intensive chemotherapy: final results of the randomized phase III study of the European Organisation for Rese. J Clin Oncol. 2011;29:1987-96.

14. Garcia-Manero G, Jabbour E, Borthakur G, Faderl S, Estrov Z, Yang $\mathrm{H}$, et al. Randomized open-label phase ii study of decitabine in patients with low- or intermediate-risk myelodysplastic syndromes. J Clin Oncol. 2013;31:2548-53.

15. Jabbour E, Short NJ, Montalban-Bravo G, Huang X, BuesoRamos C, Qiao W, et al. Randomized phase 2 study of low-dose decitabine vs low-dose azacitidine in lower-risk MDS and MDS/ MPN. Blood. 2017;130:1514-22.

16. Thépot S, Ben Abdelali R, Chevret S, Renneville A, BeyneRauzy O, Prébet T, et al. A randomized phase II trial of azacitidine \pm epoetin- $\beta$ in lower-risk myelodysplastic syndromes resistant to erythropoietic stimulating agents. Haematologica. 2016;101:918-25.

17. Drummond MW, Pocock C, Boissinot M, Mills J, Brown J, Cauchy $\mathrm{P}$, et al. A multi-centre phase 2 study of azacitidine in chronic myelomonocytic leukaemia. Leukemia. 2014;28:1570-2.

18. Braun T, Itzykson R, Renneville A, de Renzis B, Dreyfus F, Laribi K, et al. Molecular predictors of response to decitabine in advanced chronic myelomonocytic leukemia: a phase 2 trial. Blood. 2011;118:3824-31.

19. Fenaux P, Mufti GJ, Hellström-Lindberg E. Azacitidine prolongs overall survival compared with conventional care regimens in elderly patients with low bone marrow blast count acute myeloid leukemia. J Clin Oncol. 2010;28:562.

20. Dombret H, Seymour JF, Butrym A. International phase 3 study of azacytidine vs conventional care regimens in older patients with newly diagnosed AML with > 30\% blasts. Blood. 2015;126:291.

21. Döhner H, Dolnik A, Tang L, Seymour JF, Minden MD, Stone $\mathrm{RM}$, et al. Cytogenetics and gene mutations influence survival in older patients with acute myeloid leukemia treated with azacitidine or conventional care. Leukemia. 2018;32:2546-57.

22. Kantarjian H, Thomas XG, Dmoszynska A. Multicenter, randomized, open-label, phase III trial of decitabine versus patient 
choice, with physician advice, of either supportive care or lowdose cytarabine for the treatment of older patients with newly diagnosed acute myeloid leukemia. J Clin Oncol. 2012;30:2670.

23. Ali A, Penneroux J, Dal Bello R, Massé A, Quentin S, Unnikrishnan A, et al. Granulomonocytic progenitors are key target cells of azacytidine in higher risk myelodysplastic syndromes and acute myeloid leukemia. Leukemia. 2018;32:1856-60.

24. Uy GL, Duncavage EJ, Chang GS, Jacoby MA, Miller CA, Shao $\mathrm{J}$, et al. Dynamic changes in the clonal structure of MDS and AML in response to epigenetic therapy. Leukemia. 2016;31:872.

25. Unnikrishnan A, Papaemmanuil E, Beck D, Deshpande NP, Verma A, Kumari A, et al. Integrative genomics identifies the molecular basis of resistance to azacitidine therapy in myelodysplastic syndromes. Cell Rep. 2017;20:572-85.

26. Craddock C, Quek L, Goardon N. Azacytidine fails to eradicate leukemic stem/progenitor cell populations in patients with acute myeloid leukemia and myelodysplasia. Leukemia. 2013;27:1028.

27. Merlevede J, Droin N, Qin T, Meldi K, Yoshida K, Morabito M, et al. Mutation allele burden remains unchanged in chronic myelomonocytic leukaemia responding to hypomethylating agents. Nat Commun. 2016;7:10767.

28. Itzykson R, Kosmider O, Cluzeau T, Mansat-De Mas V, Dreyfus $\mathrm{F}$, Beyne-Rauzy $\mathrm{O}$, et al. Impact of TET2 mutations on response rate to azacitidine in myelodysplastic syndromes and low blast count acute myeloid leukemias. Leukemia. 2011;25:1147-52.

29. Bejar R, Lord A, Stevenson K, Bar-Natan M, Pérez-Ladaga A, Zaneveld J, et al. TET2 mutations predict response to hypomethylating agents in myelodysplastic syndrome patients. Blood. 2014; 124:2705-12.

30. Traina F, Visconte V, Elson P, Tabarroki A, Jankowska AM, Hasrouni E, et al. Impact of molecular mutations on treatment response to DNMT inhibitors in myelodysplasia and related neoplasms. Leukemia. 2014;28:78-87.

31. Cedena MT, Rapado I, Santos-Lozano A, Ayala R, Onecha E, Abaigar M, et al. Mutations in the DNA methylation pathway and number of driver mutations predict response to azacitidine in myelodysplastic syndromes. Oncotarget. 2017;8:106948-61.

32. Duchmann M, Yalniz FF, Sanna A, Sallman D, Coombs CC, Renneville A, et al. Prognostic role of gene mutations in chronic myelomonocytic leukemia patients treated with hypomethylating agents. EBioMedicine. 2018;31:174-81

33. Coombs CC, Sallman DA, Devlin SM, Dixit S, Mohanty A, Knapp K, et al. Mutational correlates of response to hypomethylating agent therapy in acute myeloid leukemia. Haematologica. 2016;101:e457-60.

34. Emadi A, Faramand R, Carter-Cooper B, Tolu S, Ford LA, Lapidus RG, et al. Presence of isocitrate dehydrogenase mutations may predict clinical response to hypomethylating agents in patients with acute myeloid leukemia. Am J Hematol. 2015;90:E77-9.

35. Welch JS, Petti AA, Miller CA, Fronick CC, O'Laughlin M, Fulton RS, et al. TP53 and decitabine in acute myeloid leukemia and myelodysplastic syndromes. N Engl J Med. 2016;375:2023-36.

36. Chang $\mathrm{C}-\mathrm{K}$, Zhao Y-S, Xu F, Guo J, Zhang Z, He Q, et al. TP53 mutations predict decitabine-induced complete responses in patients with myelodysplastic syndromes. Br J Haematol. 2017;176:600-8.

37. Montalban-Bravo G, Takahashi K, Patel K, Wang F, Xingzhi S, Nogueras GM, et al. Impact of the number of mutations in survival and response outcomes to hypomethylating agents in patients with myelodysplastic syndromes or myelodysplastic/myeloproliferative neoplasms. Oncotarget. 2018;9:9714-27.

38. Desoutter J, Gay J, Berthon C, Ades L, Gruson B, Geffroy S, et al. Molecular prognostic factors in acute myeloid leukemia receiving first-line therapy with azacitidine. Leukemia. 2015;30:1416.
39. Shen L, Kantarjian H, Guo Y, Lin E, Shan J, Huang X, et al. DNA methylation predicts survival and response to therapy in patients with myelodysplastic syndromes. J Clin Oncol. 2009;28:605-13.

40. Fandy TE, Herman JG, Kerns P. Early epigenetic changes and DNA damage do not predict clinical response in an overlapping schedule of 5-azacytidine and entinostat in patients with myeloid malignancies. Blood. 2009;114:2764.

41. Li S, Garrett-Bakelman FE, Chung SS, Sanders MA, Hricik T, Rapaport F, et al. Distinct evolution and dynamics of epigenetic and genetic heterogeneity in acute myeloid leukemia. Nat Med. 2016;22:792.

42. Meldi K, Qin T, Buchi F, Droin N, Sotzen J, Micol J-B, et al. Specific molecular signatures predict decitabine response in chronic myelomonocytic leukemia. J Clin Invest. 2015;125:1857-72.

43. Santini V, Allione B, Zini G, Gioia D, Lunghi M, Poloni A, et al. A phase II, multicentre trial of decitabine in higher-risk chronic myelomonocytic leukemia. Leukemia. 2018;32:413-8.

44. Liu Y, Siejka P, Velikova G, Yuan F, Tomkova M, Bai C, et al. Bisulfite-free, Base-resolution, and quantitative sequencing of cytosine modifications. bioRxiv. 2018;1:307538.

45. Cheng JX, Chen L, Li Y, Cloe A, Yue M, Wei J, et al. RNA cytosine methylation and methyltransferases mediate chromatin organization and 5-azacytidine response and resistance in leukaemia. Nat Commun. 2018;9:2286.

46. Hubeek I, Stam RW, Peters GJ, Broekhuizen R, Meijerink JPP, van Wering ER, et al. The human equilibrative nucleoside transporter 1 mediates in vitro cytarabine sensitivity in childhood acute myeloid leukaemia. Br J Cancer. 2005;93:1388-94.

47. Wu P, Geng S, Weng J, Deng C, Lu Z, Luo C, et al. The hENT1 and DCK genes underlie the decitabine response in patients with myelodysplastic syndrome. Leuk Res. 2015;39:216-20.

48. Qin T, Castoro R, Ahdab S. Mechanisms of resistance to decitabine in the myelodysplastic syndrome. PLoS One. 2011;6:e23372.

49. Valencia A, Masala E, Rossi A, Martino A, Sanna A, Buchi F, et al. Expression of nucleoside-metabolizing enzymes in myelodysplastic syndromes and modulation of response to azacitidine. Leukemia. 2014;28:621-8.

50. Tibaldi C, Giovannetti E, Tiseo M, Leon LG, D'Incecco A, Loosekoot $\mathrm{N}$, et al. Correlation of cytidine deaminase polymorphisms and activity with clinical outcome in gemcitabine-/platinumtreated advanced non-small-cell lung cancer patients. Ann Oncol. 2012;23:670-7.

51. Hyo Kim L, Sub Cheong H, Koh Y, Ahn K-S, Lee C, Kim $\mathrm{H}-\mathrm{L}$, et al. Cytidine deaminase polymorphisms and worse treatment response in normal karyotype AML. J Hum Genet. 2015;60:749-54.

52. Ades L, Guerci-Bresler A, Cony-Makhoul P, Legros L, Sebert M, Braun T, Delaunay J, Desseaux K, Chevret S, Fenaux P. A phase II study of the efficacy and safety of an intensified schedule of azacytidine in intermediate- 2 and high-risk patients with myelodysplastic syndromes: a study by the Groupe Francophone des Myelodysplasies (GFM). Haematologica. 2019;104(4):e131-3. https://doi.org/10.3324/haematol.2018.203885.

53. Schroeder T, Rautenberg C, Haas R, Germing U, Kobbe G. Hypomethylating agents for treatment and prevention of relapse after allogeneic blood stem cell transplantation. Int J Hematol Jpn. 2018;107:138-50.

54. de Lima M, Oran B, Champlin RE, Papadopoulos EB, Giralt SA, Scott BL, et al. CC-486 maintenance after stem cell transplantation in patients with acute myeloid leukemia or myelodysplastic syndromes. Biol Blood Marrow Transplant. 2018;24:2017-24.

55. Blum W, Sanford BL, Klisovic R, DeAngelo DJ, Uy G, Powell BL, et al. Maintenance therapy with decitabine in younger adults with acute myeloid leukemia in first remission: a phase 
2 Cancer and Leukemia Group B Study (CALGB 10503). Leukemia. 2016;31:34.

56. Grövdal M, Karimi M, Khan R, Aggerholm A, Antunovic $\mathrm{P}$, Astermark $\mathrm{J}$, et al. Maintenance treatment with azacytidine for patients with high-risk myelodysplastic syndromes (MDS) or acute myeloid leukaemia following MDS in complete remission after induction chemotherapy. Br J Haematol. 2010;150:293-302.

57. Boumber Y, Kantarjian H, Jorgensen J, Wen S, Faderl S, Castoro $\mathrm{R}$, et al. A randomized study of decitabine versus conventional care for maintenance therapy in patients with acute myeloid leukemia in complete remission. Leukemia. 2012;26:2428.

58. Huls G, Chitu DA, Havelange V, Jongen-Lavrencic M, Loosdrecht AA, Biemond BJ, Sinnige H, Hodossy B, Graux C, Kooy RVM, Weerdt O, Breems D, Klein S, Kuball J, Deeren D, Terpstra W, Vekemans MC, Ossenkoppele GJ, Vellenga E, Löwenberg B, Dutch-Belgian Hemato-Oncology Cooperative Group (HOVON). Azacitidine maintenance after intensive chemotherapy improves DFS in older AML patients. Blood. 2019;133(13):1457-64. https://doi.org/10.1182/blood-2018-10879866.

59. Platzbecker U, Middeke JM, Sockel K, Herbst R, Wolf D, Baldus CD, et al. Measurable residual disease-guided treatment with azacitidine to prevent haematological relapse in patients with myelodysplastic syndrome and acute myeloid leukaemia (RELAZA2): an open-label, multicentre, phase 2 trial. Lancet Oncol. 2018;19:1668-79.

60. Fraison J-B, Mekinian A, Grignano E, Kahn J-E, Arlet J-B, Decaux $\mathrm{O}$, et al. Efficacy of Azacitidine in autoimmune and inflammatory disorders associated with myelodysplastic syndromes and chronic myelomonocytic leukemia. Leuk Res. 2016;43:13-7.

61. Laille E, Shi T, Garcia-Manero G, Cogle CR, Gore SD, Hetzer $\mathrm{J}$, et al. Pharmacokinetics and pharmacodynamics with extended dosing of CC-486 in patients with hematologic malignancies. PLoS One. 2015;10:e0135520.

62. Savona MR, Malcovati L, Komrokji R, Tiu RV, Mughal TI, Orazi A, et al. An international consortium proposal of uniform response criteria for myelodysplastic/myeloproliferative neoplasms (MDS/ MPN) in adults. Blood. 2015;125:1857-65.

63. Garcia-Manero G, Gore SD, Kambhampati S, Scott B, Tefferi A, Cogle CR, et al. Efficacy and safety of extended dosing schedules of CC-486 (oral azacitidine) in patients with lower-risk myelodysplastic syndromes. Leukemia. 2015;30:889.

64. Roboz GJ, Kantarjian HM, Yee KWL, Kropf PL, O'Connell CL, Griffiths EA, et al. Dose, schedule, safety, and efficacy of guadecitabine in relapsed or refractory acute myeloid leukemia. Cancer. 2018;124:325-34.

65. Kantarjian HM, Roboz GJ, Kropf PL, Yee KWL, O'Connell CL, Tibes R, et al. Guadecitabine (SGI-110) in treatmentnaive patients with acute myeloid leukaemia: phase 2 results from a multicentre, randomised, phase 1/2 trial. Lancet Oncol. 2017;18:1317-26.

66. Issa JPJ, Roboz G, Rizzieri D, Jabbour E, Stock W, O'Connell C, et al. Safety and tolerability of guadecitabine (SGI-110) in patients with myelodysplastic syndrome and acute myeloid leukaemia: a multicentre, randomised, dose-escalation phase 1 study. Lancet Oncol. 2015;16:1099-110.

67. Garcia-Manero G, Griffiths EA, Roboz GJ, Busque L, Wells $\mathrm{RA}$, Odenike $\mathrm{O}$, et al. A phase 2 dose-confirmation study of oral ASTX727, a combination of oral decitabine with a cytidine deaminase inhibitor (CDAi) cedazuridine (E7727), in subjects with myelodysplastic syndromes (MDS). Blood. 2017;130:4274.

68. Cameron EE, Bachman KE, Myohanen S. Synergy of demethylation and histone deacetylase inhibition in the re-expression of genes silenced in cancer. Nat Genet. 1999;21:103.
69. Prébet T, Gore SD, Esterni B, Gardin C, Itzykson R, Thepot S, et al. Outcome of high-risk myelodysplastic syndrome after azacitidine Treatment failure. J Clin Oncol. 2011;29:3322-7.

70. Issa J-P, Garcia-Manero G, Huang X, Cortes J, Ravandi F, Jabbour E, et al. Results of phase 2 randomized study of low-dose decitabine with or without valproic acid in patients with myelodysplastic syndrome and acute myelogenous leukemia. Cancer. 2015;121:556-61.

71. Ades L, Guerci A, Laribi K, Peterlin P, Vey N, Thepot S, et al. A randomized Phase II study of azacitidine (AZA) alone or with lenalidomide (LEN), valproic acid (VPA) or idarubicin (IDA) in higher-risk MDS: GFM pick a winner trial. Blood. 2018;132:467.

72. Craddock CF, Houlton AE, Quek LS, Ferguson P, Gbandi E, Roberts $\mathrm{C}$, et al. Outcome of azacitidine therapy in acute myeloid leukemia is not improved by concurrent vorinostat therapy but is predicted by a diagnostic molecular signature. Clin Cancer Res. 2017;23:6430-40.

73. Sekeres MA, Othus M, List AF, Odenike O, Stone RM, Gore $\mathrm{SD}$, et al. Randomized Phase II study of azacitidine alone or in combination with lenalidomide or with vorinostat in higher-risk myelodysplastic syndromes and chronic myelomonocytic leukemia: North American Intergroup Study SWOG S1117. J Clin Oncol. 2017;35:2745-53.

74. Garcia-Manero G, Montalban-Bravo G, Berdeja JG, Abaza Y, Jabbour E, Essell J, et al. Phase 2, randomized, double-blind study of pracinostat in combination with azacitidine in patients with untreated, higher-risk myelodysplastic syndromes. Cancer. 2017;123:994-1002.

75. Prebet T, Sun Z, Figueroa ME, Ketterling R, Melnick A, Greenberg PL, et al. Prolonged administration of azacitidine with or without entinostat for myelodysplastic syndrome and acute myeloid leukemia with myelodysplasia-related changes: results of the US Leukemia Intergroup trial E1905. J Clin Oncol. 2014;32:1242-8.

76. Krönke J, Fink EC, Hollenbach PW, MacBeth KJ, Hurst SN, Udeshi ND, et al. Lenalidomide induces ubiquitination and degradation of CK1 $\alpha$ in $\operatorname{del}(5 q)$ MDS. Nature. 2015;523:183.

77. McGraw KL, Basiorka AA, Johnson JO, Clark J, Caceres G, Padron E, et al. Lenalidomide induces lipid raft assembly to enhance erythropoietin receptor signaling in myelodysplastic syndrome progenitors. PLoS One. 2014;9:e114249.

78. Kantarjian H, Faderl S, Garcia-Manero G, Luger S, Venugopal $\mathrm{P}$, Maness L, et al. Oral sapacitabine for the treatment of acute myeloid leukaemia in elderly patients: a randomised phase 2 study. Lancet Oncol. 2012;13:1096-104.

79. Kantarjian HM, Begna KH, Altman JK, Goldberg SL, Sekeres MA, Strickland SA, et al. Results of a Phase 3 study of elderly patients with newly diagnosed AML treated with sapacitabine and decitabine administered in alternating cycles. Blood. 2017;130:891.

80. Tan J, Chen S, Xu L, Lu S, Zhang Y, Chen J, et al. Increasing frequency of $\mathrm{T}$ cell immunosuppressive receptor expression in $\mathrm{CD} 4$ + and CD8 + T cells may related to $t$ cell exhaustion and immunosuppression in Patients with AML. Blood. 2016;128:5166.

81. Yang H, Bueso-Ramos C, DiNardo C, Estecio MR, Davanlou M, Geng Q-R, et al. Expression of PD-L1, PD-L2, PD-1 and CTLA4 in myelodysplastic syndromes is enhanced by treatment with hypomethylating agents. Leukemia. 2013;28:1280.

82. Berger R, Rotem-Yehudar R, Slama G, Landes S, Kneller A, Leiba M, et al. Phase I safety and pharmacokinetic study of CT-011, a humanized antibody interacting with PD-1, in patients with advanced hematologic malignancies. Clin Cancer Res. 2008;14:3044-51.

83. Daver N, Garcia-Manero G, Basu S, Boddu PC, Alfayez M, Cortes JE, et al. Efficacy, safety, and biomarkers of response to azacitidine and nivolumab in relapsed/refractory acute myeloid 
leukemia: a nonrandomized, open-label. Phase II Study. Cancer Discov. 2018;9:370.

84. Garcia-Manero G, Daver NG, Montalban-Bravo G, Jabbour EJ, DiNardo CD, Kornblau SM, et al. A Phase II study evaluating the combination of nivolumab (Nivo) or ipilimumab (Ipi) with azacitidine in pts with previously treated or untreated myelodysplastic syndromes (MDS). Blood. 2016;128:344.

85. Lagadinou ED, Sach A, Callahan K, Rossi RM, Neering SJ, Minhajuddin M, et al. BCL-2 inhibition targets oxidative phosphorylation and selectively eradicates quiescent human leukemia stem cells. Cell Stem Cell. 2013;12:329-41.

86. Pollyea DA, Stevens BM, Jones CL, Winters A, Pei S, Minhajud$\operatorname{din} \mathrm{M}$, et al. Venetoclax with azacitidine disrupts energy metabolism and targets leukemia stem cells in patients with acute myeloid leukemia. Nat Med. 2018;24:1859-66.

87. Konopleva M, Pollyea DA, Potluri J, Chyla B, Hogdal L, Busman T, et al. Efficacy and biological correlates of response in a Phase II study of venetoclax monotherapy in patients with acute myelogenous leukemia. Cancer Discov. 2016;6:1106-17.

88. Bogenberger JM, Delman D, Hansen N, Valdez R, Fauble V, Mesa RA, et al. Ex vivo activity of BCL-2 family inhibitors ABT-199 and ABT-737 combined with 5-azacytidine in myeloid malignancies. Leuk Lymphoma. 2015;56:226-9.

89. DiNardo CD, Pratz K, Pullarkat V, Jonas BA, Arellano M, Becker PS, et al. Venetoclax combined with decitabine or azacitidine in treatment-naive, elderly patients with acute myeloid leukemia. Blood. 2019;133:7-17.

90. DiNardo CD, Rausch CR, Benton C, Kadia T, Jain N, Pemmaraju $\mathrm{N}$, et al. Clinical experience with the BCL2-inhibitor venetoclax in combination therapy for relapsed and refractory acute myeloid leukemia and related myeloid malignancies. Am J Hematol. 2018;93:401-7.
91. Stein EM, DiNardo CD, Pollyea DA, Fathi AT, Roboz GJ, Altman $\mathrm{JK}$, et al. Enasidenib in mutant IDH2 relapsed or refractory acute myeloid leukemia. Blood. 2017;130:722-31.

92. DiNardo CD, Stein EM, de Botton S, Roboz GJ, Altman JK, Mims AS, et al. Durable remissions with ivosidenib in IDH1-mutated relapsed or refractory AML. N Engl J Med. 2018;378:2386-98.

93. DiNardo CD, Stein AS, Fathi AT, Montesinos P, Odenike O, Kantarjian HM, et al. Mutant isocitrate dehydrogenase (mIDH) inhibitors, enasidenib or ivosidenib, in combination with azacitidine (AZA): preliminary results of a phase $1 \mathrm{~b} / 2$ study in patients with newly diagnosed acute myeloid leukemia (AML). Blood. 2017;130:639.

94. Swords RT, Erba HP, DeAngelo DJ, Bixby DL, Altman JK, Maris M, et al. Pevonedistat (MLN4924), a First-in-Class NEDD8-activating enzyme inhibitor, in patients with acute myeloid leukaemia and myelodysplastic syndromes: a phase 1 study. Br J Haematol. 2015;169:534-43.

95. Smith PG, Traore T, Grossman S, Narayanan U, Carew JS, Lublinksky A, et al. Azacitidine/decitabine synergism with the NEDD8-activating enzyme inhibitor MLN4924 in pre-clinical AML models. Blood. 2011;118:578.

96. Swords RT, Coutre S, Maris MB, Zeidner JF, Foran JM, Cruz $\mathrm{J}$, et al. Pevonedistat, a first-in-class NEDD8-activating enzyme inhibitor, combined with azacitidine in patients with AML. Blood. 2018;131:1415-24.

Publisher's Note Springer Nature remains neutral with regard to jurisdictional claims in published maps and institutional affiliations. 